\title{
n \\ Children and adolescents treated for post-traumatic stress disorder at the Free State Psychiatric Complex
}

\author{
F J W Calitz, ${ }^{1}$ BA (Hons), MA (Clin Psych), DPhil; N J de Jongh²; A Horn'; ${ }^{2}$ L Nel'; G Joubert, ${ }^{3}$ BA, MSc \\ ${ }^{1}$ Department of Psychiatry, Faculty of Health Sciences, University of the Free State, Bloemfontein, South Africa \\ ${ }^{2}$ MB ChB students, Faculty of Health Sciences, University of the Free State, Bloemfontein, South Africa \\ ${ }^{3}$ Department of Biostatistics, Faculty of Health Sciences, University of the Free State, Bloemfontein, South Africa
}

Corresponding author: FJ W Calitz (calitzfjw@fshealth.gov.za)

\begin{abstract}
Background. Children and adolescents can develop post-traumatic stress disorder (PTSD) after exposure to a range of traumatic events, including domestic, political or community violence, violent crime, physical and sexual abuse, hijacking, witnessing a violent crime and motor vehicle accidents. This is particularly critical given the substantial challenge that PTSD poses to the healthy physical, cognitive and emotional development of children and adolescents.

Methods. The clinical records of 1229 children (age 2 - 11 years) and adolescents (age 12 - 18 years) treated at the Child Mental Health Unit of the Free State Psychiatric Complex (FSPC) were screened for the diagnosis of PTSD and analysed for the purpose of this study.

Results. Forty-nine (4.0\%) of the children and adolescents treated at the unit were diagnosed with PTSD, of whom most were female (63.3\%). Approximately $22 \%$ of the participants had comorbid major depressive disorder. The main traumatic event in both groups was witnessing the death of a close relative (32.7\%), followed by sexual assault (25\%), rape (25\%) and physical attack (10.2\%). Associated stressors identified included problems at school (55.1\%), isolation (39\%), fear or anxiety (37\%), problematic family relationships (29\%), emotional (27\%) and physical (23\%) abuse, and lack of social support (23\%). Most of the participants (59.2\%) received psychotherapy.

Conclusions. Children and adolescents referred to the FSPC are also exposed to traumatic events which lead to the development of PTSD. The Free State is a sprawling province with remote areas where specialist services and facilities are limited. It is therefore recommended that preventive programmes, training opportunities and consultation services are implemented to identify and treat children and adolescents with PTSD. Schools with limited access to psychological services and large classrooms, impeding the diagnosis and treatment of PTSD specifically, face similar challenges. Reinforcement of professional services and the upgrading of facilities will decrease the burden on the Child Mental Health Unit, but will require collaborative efforts from role players such as the National Departments of Health and Education.
\end{abstract}

S Afr J Psych 2014;20(1):15-20. DOI:10.7196/SAJP.441

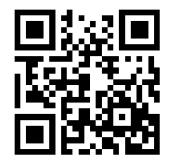

Children and adolescents can develop post-traumatic stress disorder (PTSD) after exposure to a range of traumatic events, including domestic, political or community violence, violent crime, sexual abuse, hijacking and motor vehicle accidents. This is particularly critical given the substantial challenge that PTSD poses to the healthy physical, cognitive and emotional development of children and adolescents. ${ }^{[1]}$ For example, normal daily living is influenced by the traumatic event - it changes the child's/adolescent's expectations, attitude, cautions, interactions and behaviour. Children and adolescents with PTSD lose valuable friendships; they are irritable and may exhibit pervasive personality changes that disrupt and impair their own and their family's lives. They are also prone to selfpunishment or substance abuse..$^{[2,3]}$

Several South African (SA) studies noted high rates of traumatisation and PTSD among youth. Seedat et al., ${ }^{[4]}$ in their study on exposure to trauma and post-traumatic stress symptoms in a cohort of 2041 boys and girls in urban African schools, found that the most common traumas were witnessing violence, being robbed or mugged, and witnessing a family member being hurt or killed. The most common PTSD symptoms in these individuals were: $(i)$ avoidance of activities, places or people that aroused recollections of the trauma; (ii) avoidance of thoughts, feelings or conversations associated with the trauma; (iii) irritability or outbursts of anger; and (iv) intense psychological distress at exposure to traumatic reminders. A similar study by Peltzer ${ }^{[5]}$ on rural children in SA found that $67 \%$ had directly or vicariously experienced a traumatic event, while $8 \%$ fulfilled the criteria for PTSD.

In Cape Town, a retrospective chart review found PTSD to be one of the most common disorders at the Child and Adolescent Psychiatry Unit at Tygerberg Hospital. ${ }^{[6]}$ In a community study in Khayelitsha, Ensink et al. ${ }^{[7]}$ used self-report measures to determine exposure to violence, as well as structured questionnaires and nonstandardised clinical assessments to elicit symptoms and make psychiatric diagnoses in children aged $6-16$ years. All children reported exposure to indirect violence. Ninety-five per cent had witnessed violent events, $56 \%$ had experienced violence themselves, and $22 \%$ met the criteria for PTSD. The most commonly reported PTSD symptoms were the avoidance of thoughts and activities associated with the trauma, difficulties in sleeping and hypervigilance. 
A survey of 307 grade 10 pupils in the Western Cape Province found that adolescents reported an average of 3.5 traumatic childhood experiences, and $12.1 \%$ met the Diagnostic and Statistical Manual of Mental Disorders (DSM)-IV criteria for PTSD based on self-report measures. The most commonly reported symptoms were avoiding thoughts about the event (34.4\%), irritability (28.2\%), difficulty showing emotion (26.5\%), emotional upset at being reminded of the trauma (24.9\%) and intrusive recollections of the event (19.4\%). A significant positive correlation between multiple trauma exposure and PTSD symptoms was also found. ${ }^{[8]}$

PTSD is defined in the DSM-IV ${ }^{[9]}$ as a condition following exposure to an extreme traumatic stressor involving threat to life, safety or physical integrity, either experienced or witnessed directly by the child/adolescent or affecting someone close to them. In addition to such exposure, the child/adolescent must have at least one re-experiencing symptom such as recurrent intrusive and distressing recollections or dreams about the event, or intense psychological or physiological reactions to reminders of the event; at least three symptoms of persistent avoidance of trauma-related stimuli or affective numbing; and at least two hyper-arousal symptoms. The duration of these symptoms must be more than one month, and the disturbance must cause clinically significant distress or functional impairment. ${ }^{[10]}$

Exposure to traumatic events is the main causative factor in the development of PTSD. ${ }^{[1]}$ Children and adolescents are increasingly exposed to extreme traumatic events, ${ }^{[12-16]}$ such as hostilities at school, motor vehicle accidents, domestic violence, and physical and sexual abuse, including rape, murder, hijacking, witnessing a violent crime and political violence.

According to Terr, ${ }^{[17]}$ PTSD presents somewhat differently in children than in adults. Most children have the following symptoms: (i) visualised or otherwise repeatedly perceived memories of the event, which occur when the child is bored or at rest, rather than sudden flashbacks as in adults; (ii) repetitive behaviours in which the child re-enacts the traumatic event in unsatisfying play or in other behaviours; (iii) distressing dreams of the event that may change over the course of several weeks into generalised nightmares of monsters or other upsetting events; (iv) trauma-specific fears are pronounced in children, but may not be so for adults (e.g. trauma that occurred at night could result in the child becoming nervous at bedtime); $(v)$ 'omen' formation in children - a belief in the ability to foresee future dreadful events; (vi) changes in attitudes about people, life and the future, and the belief that life will be too short to include becoming adult, or other pessimistic expectations may take hold; and ( $v i i$ ) often, marked personality changes.

Children and adolescents are prone to the development of PTSD after exposure to a traumatic event. Children are variably vulnerable to the psychological effects of trauma, owing to a range of developmental factors, such as level of cognitive and emotional maturity. ${ }^{[18]}$ Adolescents face a number of new phase-specific developmental demands including the acquisition of coherent identities, establishing relations with peers and developing independence from parents. ${ }^{[19]}$

International studies have also highlighted high rates of traumatisation and PTSD in children and adolescents. For example, Holford et al. ${ }^{[20]}$ reported that $25-100 \%$ of children and adolescents exposed to sudden unanticipated violence develop PTSD. Giaconia et al., ${ }^{[21]}$ in their study on trauma and PTSD in a community population of older adolescents, found that $\sim 43 \%$ of the adolescents experienced trauma such as rape, assault or sudden injury by age 18 years, and $11.7 \%$ were exposed to trauma as early as age 14 years. The peak age at which PTSD developed was 16 - 17 years, with a mean age of 16 years. Davidson and Smith ${ }^{[22]}$ reported that PTSD was three times more likely to develop when traumatic events were experienced before the age of 11 years. Lastly, Weine et al. ${ }^{[23]}$ studied 75 male and female adolescent inpatients aged $13-18$ years and found that $81 \%$ reported experiencing at least one traumatic event in childhood. The loss of a parent or caregiver was the most frequent type of trauma reported. In addition, $13 \%$ of subjects were victims of physical abuse, $16 \%$ of sexual abuse, $19 \%$ of domestic violence, and $11 \%$ had suffered gross neglect.

Adolescents are also at greater risk of developing PTSD than either adults or children. For instance, adolescents are more likely to engage in a variety of risky behaviours, such as gang-related activities, teenage pregnancies, substance abuse and peer group pressure. ${ }^{[2]}$ Nooner et al. ${ }^{[24]}$ reported that the prevalence of PTSD among adolescents was 3 - 57\%, and that age, gender, type of trauma and repeated trauma were important factors related to the increase in the number of adolescents with the disorder. Suicide, substance abuse, poor social support, academic problems and poor physical health were risk factors associated with PTSD in adolescence.

Other factors contributing to vulnerablility to PTSD in childhood and adolescence are sexual or physical trauma, low self-esteem, separation of one's parents before the age of 10 years, a prior psychiatric disorder, a psychiatric disorder in first-degree relatives, and female gender. ${ }^{[25]}$ The interaction of risk factors along with the severity of the trauma appears to influence who will and will not develop PTSD. Parental stress, single-parent households, foster placements, maltreatment, lower socioeconomic status, parental psychopathology and poor healthcare are also factors that increase the risk of developing PTSD. ${ }^{[2]}$ Long-lasting and intense traumatic events are also known to increase the prevalence of PTSD. ${ }^{[13]}$

Gender differences were observed in a study by Cauffman et al. ${ }^{[26]}$ of 96 incarcerated adolescents who had been exposed to violence; females were $\sim 50 \%$ more likely to experience PTSD than their male equivalents. Males were more likely to report witnessing a violent event, while females were more likely to report being a victim of violence. In addition, females were found to exhibit less restraint, potentially leading to future offences without appropriate intervention or treatment.

PTSD may coexist with, or be misdiagnosed as a behavioural disorder such as attention-deficit hyperactivity disorder (ADHD) or conduct disorder. Particularly in younger children who are less able to verbalise their anxiety, PTSD-related irritability, sleep difficulties and difficulty concentrating may present as classic ADHD. Eliciting a history of trauma exposure and evaluating the timing of symptoms may be important in distinguishing these disorders. ${ }^{[10]}$ Rose et al. ${ }^{[27]}$ asserted that a diagnosis of PTSD by the age of 18 years significantly increased the comorbidity of disorders such as anxiety, depression, and alcohol and drug dependency. Famularo et al. ${ }^{[28]}$ examined the comorbidity of psychiatric disorders in children and adolescents aged 6 - 17 years, in juvenile/family court after experiencing child abuse or trauma. They found that a diagnosis of PTSD significantly correlated 
with anxiety, suicidal ideation, ADHD, psychotic disorders and mood disorders.

Although research on the psychological treatment of children and adolescents with PTSD is very limited in comparison with adults, some studies ${ }^{[20,25,29,30]}$ have found cognitive-behavioural approaches combined with family or group treatment to be beneficial. Medication is helpful to treat secondary symptoms and is more likely to be useful if administered soon after the onset of symptoms. ${ }^{[29,30]}$

In summary, it is evident that children and adolescents in SA are still exposed to high levels of trauma and many develop PTSD. In our clinical experience, the same situation confronts children and adolescents in the Free State Province. A literature search did not reveal any studies on PTSD in children and adolescents conducted in the province; hence the need for our study. Secondly, there are increasingly limited resources, such as few school psychologists, large classes in schools and limited mental health services for children and adolescents in the province, which collectively makes it difficult to identify and treat children and adolescents with PTSD. Finally, increased awareness among caregivers of a condition that may go unnoticed due to its characteristic symptoms of avoidance, is expected to improve the identification and treatment of children and adolescents suffering from PTSD. Consequently, we identified a need to investigate the profile of PTSD in children and adolescents.

\section{Objective}

The objective of our study was to profile children and adolescents treated for PTSD at the Free State Psychiatric Complex (FSPC) from 1 January 2003 to 31 December 2011. Specific aims were to investigate: (i) the demographic profile of children and adolescents with PTSD; (ii) extreme traumatic events; (iii) the profile of stressors associated with PTSD; (iv) comorbidity of other conditions in children and adolescents diagnosed with PTSD; and $(v)$ the types of psychiatric treatment that children and adolescents with PTSD received.

\section{Methods}

We conducted a descriptive, retrospective study. A total of 1229 children (age $2-11$ years; $n=660 ; 53.7 \%$ ) and adolescents (age 12 - 18 years; $n=569 ; 46.3 \%)$ were treated at the Child Mental Health Unit of the FSPC between 1 January 2003 and 31 December 2011. Twenty (3.0\%) children and 29 (5.1\%) adolescents were diagnosed with PTSD; therefore, the data of a total of $49(4.0 \%)$ children and adolescents were analysed for the purpose of this study.

Participants were evaluated and diagnosed on admission to the unit by the multi-professional team of the Child Mental Health Unit according to DSM-IV criteria. ${ }^{[2]}$ The team included a child and adolescent psychiatrist, a clinical psychologist, a psychiatry registrar, a clinical psychology intern, psychiatric professional nurses, a social worker and an occupational therapist.

A data-capture sheet was compiled and used to record the relevant information from the participants' clinical files. This information provided a basic demographic profile, possible contributing factors, comorbidity and the different types of psychiatric treatment received. A pilot study using ten files of participants preceded the main study. The research protocol was approved by the Ethics Committee of the Faculty of Health Sciences, University of the Free State (UFS).
Permission to access the patient files was obtained from the chief executive officer of the FSPC.

Data analysis was performed by the Department of Biostatistics, UFS. Results were summarised as frequencies and percentages in the case of categorical variables, and means or percentiles for numerical variables.

\section{Results and discussion \\ Sociodemographic information}

Sociodemographic data are summarised in Table 1. The median age of the children and adolescents diagnosed with PTSD was 7 (range 1 - 12) and 12 years (range 13 - 18), respectively. Most (65.3\%) participants were female, and the majority were black (65.3\%). More than $40 \%$ of the total group (children $35.0 \%$; adolescents $44.8 \%$ ) had lost one or both of their parents. Nearly $64 \%$ had a family structure of a single parent or no parent at all. This finding supports Davis and Siegel's ${ }^{[25]}$ and Breslau' ${ }^{[31]}$ view that factors such as separation from

Table 1. Participant sociodemographic data

\begin{tabular}{|c|c|c|c|}
\hline Variable & $\begin{array}{l}\text { Children } \\
(N=20) \\
n(\%)\end{array}$ & $\begin{array}{l}\text { Adolescents } \\
(N=29) \\
n(\%)\end{array}$ & $\begin{array}{l}\text { Total } \\
(N=49) \\
n(\%)\end{array}$ \\
\hline \multicolumn{4}{|l|}{ Gender } \\
\hline Male & $8(40.0)$ & $10(34.5)$ & $18(36.7)$ \\
\hline Female & $12(60.0)$ & $19(65.5)$ & $31(63.3)$ \\
\hline \multicolumn{4}{|l|}{ Race } \\
\hline Black & $13(65.0)$ & $19(65.5)$ & $32(65.3)$ \\
\hline White & $5(25.0)$ & $8(27.6)$ & $13(26.5)$ \\
\hline Coloured & $2(10.0)$ & $2(6.9)$ & $4(8.2)$ \\
\hline \multicolumn{4}{|l|}{ Deceased parents } \\
\hline Father & $4(20.0)$ & $7(24.2)$ & $11(22.5)$ \\
\hline Mother & $3(15.0)$ & $3(10.3)$ & $6(12.5)$ \\
\hline Both parents & $0(0)$ & $3(10.3)$ & $3(6.1)$ \\
\hline \multicolumn{4}{|c|}{ Family structure (parents) ${ }^{*}$} \\
\hline Separated & $4(20.0)$ & $2(6.9)$ & $6(12.3)$ \\
\hline Living together & $1(5.0)$ & $2(6.9)$ & $3(6.1)$ \\
\hline Remarried & $1(5.0)$ & $2(6.9)$ & $3(6.1)$ \\
\hline Divorced & $0(0)$ & $4(13.8)$ & $4(8.2)$ \\
\hline Unmarried & $5(25.0)$ & $5(17.2)$ & $10(20.4)$ \\
\hline Married & $6(30.0)$ & $6(20.7)$ & $12(24.5)$ \\
\hline Widow/widower & $4(20.0)$ & $7(24.1)$ & $11(22.5)$ \\
\hline Unknown & $0(0)$ & $1(3.4)$ & $1(2.0)$ \\
\hline \multicolumn{4}{|l|}{ Living arrangement } \\
\hline Mother & $9(45.0)$ & $11(37.9)$ & $20(40.8)$ \\
\hline Father & $1(5.0)$ & $0(0)$ & $1(2.0)$ \\
\hline Both parents & $5(25.0)$ & $6(20.7)$ & $11(22.5)$ \\
\hline Foster care & $4(20.0)$ & $5(17.2)$ & $9(18.4)$ \\
\hline Extended family & $1(5.0)$ & $4(13.8)$ & $5(10.2)$ \\
\hline Other & $0(0)$ & $3(10.3)$ & $3(6.1)$ \\
\hline
\end{tabular}


one's parents before age 10 years and changing family patterns such as divorce and remarriage, which increase the risk of molestation by stepfathers, are risk factors that predispose children and adolescents to PTSD. In this regard, it has also been stressed that family support plays an important role in decreasing some of the psychological problems associated with exposure to violence in children. ${ }^{[12]}$ Only $11(22.4 \%)$ of the participants lived with both parents, nearly $41 \%$ lived with their mothers, and only $2 \%$ lived with their fathers; the remainder were in foster care (18.4\%) or lived with extended family members $(10.2 \%)$.

\section{Number of participants evaluated per annum}

Table 2 summarises the number of participants evaluated for the first time for PTSD per annum in 2003 - 2011. A steady increase in the incidence of PTSD was observed. In 2005, no case of PTSD was diagnosed, and from 2003 to 2006, no new children presented, with a constant incidence of one adolescent in the same time period. The incidence of PTSD peaked in 2011 at $28.6 \%$ of the study population. A possible reason for the increase was the high crime rate in the province, as reflected by the main extreme traumatic stressors found in this study (Table 4), namely witnessing the death of a close relative, rape and sexual assault. According to official crime statistics for the province, a total of 4838 cases of sexual offences, 963 murders and 234 car hijackings were reported to the South African Police Service during this period. ${ }^{[32]}$ A second possibility is that the increase could have been attributed to increasing awareness of PTSD among the general population and the availability of mental health services.

\section{Associated mental disorders (comorbidity)}

Table 3 summarises the prevalence of various mental disorders associated with PTSD. Nine children had comorbid conditions (45.0\%) compared with 17 adolescents (58.6\%). Major depressive disorder (MDD) was most frequently associated with PTSD in adolescence - a finding supported by other investigators. ${ }^{[11,27,28]}$

\section{Traumatic events}

Table 4 summarises the traumatic events identified in participants. In children, the main traumatic event was witnessing the death of a close relative (30.0\%), followed by sexual assault (20.0\%); and in adolescents, witnessing the death of a close relative (34.5\%), followed by rape $(31.0 \%)$ and sexual assault $(27.6 \%)$. Most $(62.2 \%)$ of the main traumatic events identified were violent in nature, reflecting the aggressive nature of our society.

\section{Associated stressors}

Associated stressors identified in participants are listed in Table 5. The main associated stressor identified was problems at school (55.1\%), followed by isolation (39\%), fear/anxiety (37\%) and problematic family relationships (29\%). The associated stressors were similar in children and adolescents.

\section{Types of psychiatric treatment}

Table 6 summarises the types of psychiatric treatment provided to the children and adolescents with PTSD. The treatment modalities in both groups followed a similar pattern. More than half (59.2\%) of the participants received psychotherapy (mainly cognitive and behavioural therapy and play therapy), while $36.7 \%$ received a combination of psychotherapy and medication. This approach is in line with current policy to treat PTSD in children and adolescents with a combination of psychotherapy ${ }^{[1,24,29,30]}$ and medication. ${ }^{[29,30]}$

Table 2. Number of participants evaluated for PTSD per year, $2003-2011$

\begin{tabular}{llll}
\hline Year & $\begin{array}{l}\text { Children } \\
(\boldsymbol{N = 2 0}) \\
\boldsymbol{n}(\%)\end{array}$ & $\begin{array}{l}\text { Adolescents } \\
(\boldsymbol{N = 2 9 )} \\
\boldsymbol{n}(\%)\end{array}$ & $\begin{array}{l}\text { Total } \\
(\boldsymbol{N}=49) \\
\boldsymbol{n}(\%)\end{array}$ \\
\hline 2003 & $0(0)$ & $1(3.5)$ & $1(2.0)$ \\
2004 & $0(0)$ & $1(3.5)$ & $1(2.0)$ \\
2005 & $0(0)$ & $0(0)$ & $0(0)$ \\
2006 & $0(0)$ & $1(3.5)$ & $1(2.0)$ \\
2007 & $1(5.0)$ & $3(10.3)$ & $4(8.2)$ \\
2008 & $2(10.0)$ & $3(10.3)$ & $5(10.2)$ \\
2009 & $8(40.0)$ & $3(10.3)$ & $11(22.5)$ \\
2010 & $4(20.0)$ & $8(27.6)$ & $12(24.5)$ \\
2011 & $5(25.0)$ & $9(31.0)$ & $14(28.6)$ \\
& & &
\end{tabular}

Table 3. Associated mental disorders (comorbidity) diagnosed in participants with PTSD

\begin{tabular}{|c|c|c|c|}
\hline Comorbidity & $\begin{array}{l}\text { Children } \\
(N=20) \\
n(\%)\end{array}$ & $\begin{array}{l}\text { Adolescents } \\
(N=29) \\
n(\%)\end{array}$ & $\begin{array}{l}\text { Total } \\
(N=49) \\
n(\%)\end{array}$ \\
\hline MDD & $1(5.0)$ & $5(17.2)$ & $6(12.2)$ \\
\hline GAD & $1(5.0)$ & $1(3.5)$ & $2(4.1)$ \\
\hline Secondary enuresis & $1(5.0)$ & $0(0)$ & $1(2.0)$ \\
\hline ADHD & $1(5.0)$ & $1(3.5)$ & $2(4.1)$ \\
\hline Enuresis & $1(5.0)$ & $0(0)$ & $1(2.0)$ \\
\hline $\begin{array}{l}\text { ADHD and secondary } \\
\text { enuresis }\end{array}$ & $1(5.0)$ & $1(3.5)$ & $2(4.1)$ \\
\hline Psychosis & $1(5.0)$ & $1(3.5)$ & $2(4.1)$ \\
\hline RAD and enuresis & $1(5.0)$ & $0(0)$ & $1(2.0)$ \\
\hline Traumatic grief & $1(5.0)$ & $0(0)$ & $1(2.0)$ \\
\hline $\begin{array}{l}\text { Substance-related } \\
\text { disorders }\end{array}$ & $0(0)$ & $1(3.5)$ & $1(2.0)$ \\
\hline Adjustment disorder & $0(0)$ & $1(3.5)$ & $1(2.0)$ \\
\hline Bereavement & $0(0)$ & $1(3.5)$ & $1(2.0)$ \\
\hline $\begin{array}{l}\text { Conduct disorder and } \\
\text { alcohol abuse }\end{array}$ & $0(0)$ & $1(3.5)$ & $1(2.0)$ \\
\hline $\begin{array}{l}\text { Conduct disorder and } \\
\text { ODD }\end{array}$ & $0(0)$ & $1(3.5)$ & $1(2.0)$ \\
\hline ODD & $0(0)$ & $1(3.5)$ & $1(2.0)$ \\
\hline Conduct disorder & $0(0)$ & $1(3.5)$ & $1(2.0)$ \\
\hline $\begin{array}{l}\text { OCD and adjustment } \\
\text { disorder }\end{array}$ & $0(0)$ & $1(3.5)$ & $1(2.0)$ \\
\hline \multicolumn{4}{|c|}{$\begin{array}{l}\mathrm{MDD}=\text { major depressive disorder; } \mathrm{GAD}=\text { generalised anxiety disorder; } \\
\mathrm{ADHD}=\text { attention deficit hyperactivity disorder; } \mathrm{RAD}=\text { reactive attachment disorder; } \\
\mathrm{ODD}=\text { oppositional defiant disorder; } \mathrm{OCD}=\text { obsessive compulsive disorder. }\end{array}$} \\
\hline
\end{tabular}


Table 4. Traumatic events identified in children and adolescents with PTSD*

\begin{tabular}{|c|c|c|c|}
\hline Stressor & $\begin{array}{l}\text { Children } \\
(N=20) \\
n(\%)\end{array}$ & $\begin{array}{l}\text { Adolescents } \\
(N=29) \\
n(\%)\end{array}$ & $\begin{array}{l}\text { Total } \\
(N=49) \\
n(\%)\end{array}$ \\
\hline $\begin{array}{l}\text { Witnessed the death of a } \\
\text { close relative }\end{array}$ & $6(30.0)$ & $10(34.5)$ & $16(32.7)$ \\
\hline Sexual assault & $4(20.0)$ & $8(27.6)$ & $12(24.5)$ \\
\hline Rape & $3(15.0)$ & $9(31.0)$ & $12(24.4)$ \\
\hline Physical attack & $2(10.0)$ & $3(10.3)$ & $5(10.2)$ \\
\hline Bullied & $2(10.0)$ & $1(3.5)$ & $3(6.1)$ \\
\hline Robbery & $1(5.0)$ & $2(6.9)$ & $3(6.1)$ \\
\hline Serious injury to others & $3(15.0)$ & $0(0)$ & $3(6.1)$ \\
\hline $\begin{array}{l}\text { Unnatural death of } \\
\text { another person }\end{array}$ & $1(5.0)$ & $0(0)$ & $1(2.0)$ \\
\hline Abandonment by father & $1(5.0)$ & $0(0)$ & $1(2.0)$ \\
\hline Domestic violence & $1(5.0)$ & $0(0)$ & $1(2.0)$ \\
\hline Mother's boyfriend & $1(5.0)$ & $0(0)$ & $1(2.0)$ \\
\hline $\begin{array}{l}\text { Witnessed father burn } \\
\text { mother }\end{array}$ & $1(5.0)$ & $0(0)$ & $1(2.0)$ \\
\hline $\begin{array}{l}\text { Severe storm - house } \\
\text { ruined }\end{array}$ & $1(5.0)$ & $0(0)$ & $1(2.0)$ \\
\hline Motor vehicle accident & $0(0)$ & $2(6.9)$ & $2(4.1)$ \\
\hline $\begin{array}{l}\text { Mother arrested in the } \\
\text { presence of children }\end{array}$ & $0(0)$ & $2(6.9)$ & $2(4.1)$ \\
\hline Exposure to a corpse & $0(0)$ & $1(3.5)$ & $1(2.0)$ \\
\hline Adjustment & $0(0)$ & $1(3.5)$ & $1(2.0)$ \\
\hline $\begin{array}{l}\text { Mother raped in the } \\
\text { presence of children }\end{array}$ & $0(0)$ & $1(3.5)$ & $1(2.0)$ \\
\hline Framed for rape & $0(0)$ & $1(3.5)$ & $1(2.0)$ \\
\hline Family fights & $0(0)$ & $1(3.5)$ & $1(2.0)$ \\
\hline Neglected by mother & $0(0)$ & $1(3.5)$ & $1(2.0)$ \\
\hline HIV-positive & $0(0)$ & $1(3.5)$ & $1(2.0)$ \\
\hline
\end{tabular}

\section{Conclusion}

Of particular interest were our findings that only $23 \%$ of participants lived with both parents, MDD was the comorbidity most frequently associated with PTSD in adolescence, and witnessing the death of a close relative was the main traumatic event identified in both children and adolescents.

It is clear that children and adolescents referred to the FSPC are exposed to traumatic events which lead to the development of PTSD. The Free State is a sprawling province with remote areas, where specialist services and facilities are limited. Preventive programmes, training opportunities and consultation services should be implemented to identify and treat youth with PTSD. Schools with limited access to psychological services and large classes impeding the diagnosis and treatment of PTSD specifically,

\begin{tabular}{|c|c|c|c|}
\hline Stressor & $\begin{array}{l}\text { Children } \\
(N=20) \\
n(\%)\end{array}$ & $\begin{array}{l}\text { Adolescents } \\
(N=29) \\
n(\%)\end{array}$ & $\begin{array}{l}\text { Total } \\
(N=49) \\
n(\%)\end{array}$ \\
\hline Problems at school & $9(45.0)$ & $18(62.1)$ & $27(55.1)$ \\
\hline Fear/anxiety & $8(40.0)$ & $10(34.5)$ & $18(37.0)$ \\
\hline Isolation & $7(35.0)$ & $12(41.4)$ & $19(39.0)$ \\
\hline Emotional abuse & $5(25.0)$ & $8(27.6)$ & $13(27.0)$ \\
\hline Physical abuse & $1(5.0)$ & $10(34.5)$ & $11(23.0)$ \\
\hline $\begin{array}{l}\text { Problematic family } \\
\text { relationships }\end{array}$ & $4(20.0)$ & $10(34.5)$ & $14(29.0)$ \\
\hline Lack of social support & $3(15.0)$ & $8(27.6)$ & $11(23.0)$ \\
\hline Financial problems & $2(10.0)$ & $3(10.3)$ & $5(10.2)$ \\
\hline $\begin{array}{l}\text { Divorced/separated } \\
\text { parents }\end{array}$ & $2(10.0)$ & $5(17.2)$ & $7(14.3)$ \\
\hline $\begin{array}{l}\text { Arguments between } \\
\text { family members }\end{array}$ & $1(5.0)$ & $3(10.3)$ & $4(8.2)$ \\
\hline Rejection & $1(5.0)$ & $1(3.4)$ & $2(4.1)$ \\
\hline Low self-esteem & $1(5.0)$ & $2(8.7)$ & $3(6.1)$ \\
\hline $\begin{array}{l}\text { Abnormal sexual } \\
\text { behaviour }\end{array}$ & $1(5.0)$ & - & $1(2.0)$ \\
\hline Parents are depressed & $1(5.0)$ & - & $1(2.0)$ \\
\hline Chronic mental illness & - & $2(8.7)$ & $2(4.1)$ \\
\hline School refusal & - & $1(3.4)$ & $1(2.0)$ \\
\hline
\end{tabular}

Table 6. Treatment of children and adolescents with PTSD

\begin{tabular}{|c|c|c|c|}
\hline Treatment & $\begin{array}{l}\text { Children } \\
(N=20) \\
n(\%)\end{array}$ & $\begin{array}{l}\text { Adolescents } \\
(N=29) \\
n(\%)\end{array}$ & $\begin{array}{l}\text { Total } \\
(N=49) \\
n(\%)\end{array}$ \\
\hline Medication & $1(5.0)$ & $1(3.5)$ & $2(4.1)$ \\
\hline Psychotherapy & $14(70.0)$ & $15(51.7)$ & $29(59.2)$ \\
\hline Combination & $5(25.0)$ & $13(44.8)$ & $18(36.7)$ \\
\hline
\end{tabular}

face similar challenges. Reinforcement of professional services and upgrading of facilities will decrease the burden on the Mental Health Child Unit of the FSPC, but will require collaborative efforts from role players such as the National Departments of Health and Education.

Despite the significance of our findings, they should be interpreted with caution. Only children and adolescents referred to the FSPC were included in our study, thus our findings cannot be generalised to other populations. However, the significance of the study should not be underestimated; it is the first of its kind on PTSD in children and adolescents in the Free State Province. The study contributes to the important body of information profiling children and adolescents with PTSD. Importantly, further research is needed in this area. 
Acknowledgements. We thank Dr L M van der Merwe for proofreading the protocol. Dr Daleen Struwig, medical writer, Faculty of Health Sciences, is acknowledged for technical and editorial preparation of the manuscript for publication.

\section{References}

1. Kaminer D, Seedat S, Stein D. Post-traumatic disorder in children. World Psychiatry 2005;4:121-125.

2. Nader K. Understanding and Assessing Trauma in Children and Adolescents: Measures, Methods and Youth in Context. New York: Routledge, 2008.

3. Osofsky JD. Young Children and Trauma: Intervention and Treatment. London: Guilford Press, 2004:3-8.

4. Seedat S, Njenga B, Nyamai F, Vythilingum B, Stein DJ. Trauma exposure and post-traumatic stress symptoms in urban African schools: survey in Cape Town and Nairobi. Br J Psychiatry 2004;184:169-175. [http://dx.doi.org/10.1192/bjp.184.2.169]

5. Peltzer K. Posttraumatic stress symptoms in a population of rural children in South Africa. Psychol Rep 1999;85:646-650. [http://dx.doi.org/10.2466/pr0.1999.85.2.646]

6. Traut A, Kaminer D, Boshof D, Seedat S, Hawkridge S, Stein DJ. Treatment utilization an trauma characteristics of child and adolescent inpatients with posttraumatic stress disorder. Curationis 2002;25:67-72. [http://dx.doi.org/10.4102/curationis.v25i4.809]

7. Ensink K, Robertson BA, Zissis C, Leger P. Post-traumatic stress disorder in children exposed to violence. S Afr Med J 1997;87:1526-1530

8. Seedat S, van Nood E, Vythilingum B, Stein DJ, Kaminer D. School survey of exposure to violence and posttraumatic stress symptoms in adolescents. S Afr J Child Adolesc Mental Health 2000;12:38-44. [http://dx.doi.org/10.1080/16826108.2000.9632366]

9. American Psychiatric Association. Diagnostic and Statistical Manual of Mental Disorder (DSM-IV-TR). 4th ed. Washington DC: American Psychiatric Association, 1994:424-429.

10. Cohen JA. Posttraumatic stress disorder in children and adolescents. In: Sadock BJ, Sadock VA, eds. Kaplan \& Sadock's Comprehensive Textbook of Psychiatry. Baltimore: Lippincott Williams \& Wilkins, 2005:3286-3291.

11. Silva RR. Posttraumatic Stress Disorder in Children and Adolescents. New York: WW Norton and Company, 2004:1-19,27-55,142

12. Ouimette P, Brown PJ. Trauma and Substance Abuse: Causes, Consequences and Treatmen of Comorbid Disorders. Washington DC: American Psychiatric Association, 2003:243-245.

13. Suliman S, Kaminer D, Seedat S, Stein DJ. Assessing post-traumatic stress disorder in South African adolescents: Using the child and adolescent trauma survey (CATS) as a screening tool. Ann Gen Psychiatry 2005;4:2-11. [http://dx.doi.org/10.1186/1744-859X-4-2]

14. Cardena E, Croyle K. Acute Reactions to Trauma and Psychotherapy: A Multidisciplinary and International Perspective. London: Haworth Medical Press, 2005.

15. Olofsson E, Bunketorp O, Andersson A. Children and adolescents injured in traffic associated psychological consequences: A literature review. Acta Paediatr 2009;98:17-22. [http://dx.doi.org/10.1111/j.1651-2227.2008.00998.x]

16. Meiser-Stedman R, Smith P, Glucksman E, Yule W, Dalgleish T. Parent and child agreemen for acute stress disorder, post-traumatic stress disorder and other psychopathology in a prospective study of children and adolescents exposed to single-event trauma. J Abnorm Child Psychol 2007;35:191-201. [http://dx.doi.org/10.1007/s10802-006-9068-1]

17. Terr LC. Childhood traumas: An outline and overview. Am J Psychiatry 1991;148:10-20

18. Louw DA, Louw AE, Ferns I. Adolescence. In: Louw DA, Louw AE, eds. Child and Adolescent Development. Bloemfontein: Psychology Publications, 2007:278-347.

19. Nooner KB, Linares O, Batinjane J, Kramer A, Silva R, Cloitre M. Factors related to posttraumatic stress disorder in adolescence. Trauma Violence Abuse 2012;13:153-166. [http://dx.doi.org/10.1177/1524838012447698]

20. Holford L, Ziervogel C, Smith C. Child and adolescent psychiatry. In: Robertson B, Allwood C, Gagiano C, eds. Textbook of Psychiatry for Southern Africa. New York: Oxford University Press, 2001:282-322.

21. Giaconia RM, Reinherz HZ, Silverman AB, Pakiz B, Frost AK, Cohen E. Ages of onset of psychiatric disorders in a community population of older adolescents. J Am Acad Child Adolesc Psychiatry 1994;33:706-717. [http://dx.doi.org/10.1097/00004583-199406000-00012]

22. Davidson S, Smith R. Traumatic experiences in psychiatric outpatients. J Trauma Stres 1990;3:459-475. [http://dx.doi.org/10.1002/jts.2490030314]

23. Weine SM, Becker DE, Levy KN, Edell WS, McGlashan TH. Childhood traum histories in adolescent inpatients. J Trauma Stress 1997;10:291-298. [http://dx.doi. org/10.1023/A:1024834330300]

24. Nooner KB, Linares O, Batinjane J, Kramer A, Silva R, Cloitre M. Factors related to posttraumatic stress disorder in adolescence. Trauma Violence Abuse 2012;13:153-166. [http://dx.doi.org/10.1177/1524838012447698]

25. Davis L, Siegel LJ. Posttraumatic stress disorder in children and adolescents: A review and analysis. Clin Child Family Psychol Rev 2000;3:135-154. [http://dx.doi. org/10.1023/A:1009564724720]

26. Cauffman E, Feldman SS, Waterman J, Steiner H. Posttraumatic stress disorder among female juvenile offenders. J Am Acad Child and Adolesc Psychiatry 1998;37:1209-1216. [http:// dx.doi.org/10.1097/00004583-199811000-00022]

27. Rose M, Giaconia RM, Reinherz HZ, et al. Ages of onset of psychiatric disorders in a community population of older adolescents. J Am Acad Child Adolesc Psychiatry 1994;33:706-717.

28. Famularo R, Fenton T, Kinscherff R, Augustyn M. Psychiatric comorbidity in childhood post-traumatic stress disorder. Child Abuse Negl 1996;20:953-961. [http://dx.doi. org/10.1016/0145-2134(96)00084-1]

29. Keane TM, Marshall AD, Taft CT. Posttraumatic stress disorder: Etiology, epidemiology and treatment outcome. Ann Rev Clin Psychol 2006;2:161-197. [http://dx.doi.org/10.1146/ annurev.clinpsy.2.022305.095305]

30. Yule W, Canterbury R. The treatment of post-traumatic stress disorder in children and adolescents. Int Rev Psychiatry 1994;6:141-151. [http://dx.doi org/10.3109/09540269409023254]

31. Breslau N, Davis G, Andreski P, Peterson E. Traumatic events and post-traumatic stress disorder in an urban population of young adults. Arch Gen Psychiatry 1991;48:216-222. [http://dx.doi.org/10.1001/archpsyc.1991.01810270028003]

32. Crime Research and Statistics, South African Police Service. Crime in the Free State (Provincial Total) for April to March 2003/2004 - 2010/2011. ISS Africa Crime Release September 2011. http://www.issafrica.org/upload/2011 freestatecrimestats.pdf (accessed 20 November 2013). 